\title{
Análise dos spots radiofônicos no segundo turno da campanha eleitoral presidencial em 2018
}

\author{
Analysis of campaign radio spots in the second round of the 2018 \\ Brazilian presidential election
}

\section{Luciana Panke}

Pós-doutorado em Comunicação Política, UAM-México e Doutorado em Ciências da Comunicação, ECA/USP. Professora associada na graduação em Publicidade e Propaganda do Departamento de Comunicação e da Pós-graduação em Comunicação da Universidade Federal do Paraná. Curitiba - PR, Brasil. Líder do grupo de pesquisa Comunicação Eleitoral e vice-presidente da ALICE - Asociación Latinoamericana de Investigadores en Campañas Electorales.

\section{Karina Lançoni Bernardi}

Jornalista, produtora da rádio CBN Curitiba. Mestranda em Comunicação no Programa de Pós-Graduação em Comunicação (PPGCOM) da Universidade Federal do Paraná. Membro do grupo de pesquisa Comunicação Eleitoral. Aluna da especialização em Sociologia Política no Departamento de Ciência Política da Universidade Federal do Paraná.

\section{RESUMO}

Nos últimos anos, as pesquisas de comunicação política têm se focado na interpelação das novas técnicas de produção e veiculação de sentidos. É inegável a influência das plataformas digitais nos processos eleitorais; entretanto, trazemos um estudo sobre o conteúdo veiculado na tradicional mídia eletrônica: o rádio. Analisamos os spots veiculados na última semana do segundo turno da Campanha Presidencial de 2018, produzidos e disponibilizados pelos partidos no sistema de divulgação do Tribunal 
Superior Eleitoral (TSE), veiculados na programação comercial das emissoras de rádio de todo o país. Para a análise, categorizamos as temáticas dos spots eleitorais com base na metodologia desenvolvida por Panke e Cervi (2011) e na classificação definida por Virginia Beaudoux e Orlando D’Adamo (2006), como spots positivos, negativos e de contraste. Em ambas as campanhas o que prevaleceu foi a tentativa de desqualificação do adversário, com características predominantemente negativas.

Pallavras-Chave: Comunicação Política; Spots Eleitorais; Campanha Eleitoral; Campanha Presidencial; Rádio.

\section{ABSTRACT}

In recent years, political communication research has focused on the interpellation of new production techniques and the conveyance of meanings. The influence of digital platforms on electoral processes is undeniable; however, we chose to carry out a study of the content conveyed in a traditional electronic medium: the radio. We analyzed the spots broadcast in the last week of the second round of the 2018 Presidential Campaign, produced and made available by the parties in the broadcasting system of the Superior Electoral Tribunal (TSE), which were transmitted in the commercial programming of radio stations throughout the country. For the analysis, we categorized the topics of electoral spots, based on the methodology developed by Panke and Cervi (2011) and the classification defined by Virginia Beaudoux and Orlando D'Adamo (2006) as positive, negative and contrast spots. In both campaigns, what prevailed was the attempt at disqualification of the adversary, with characteristics being predominantly negative.

Keywords: Political Communication; Electoral Spots; Election Campaign; Presidential Campaign; Radio.

\section{RESUMEN}

En los últimos años, las investigaciones de comunicación política se han centrado en la interpelación de las nuevas técnicas de producción y transmisión de sentidos. Es innegable la influencia de las plataformas digitales en los procesos electorales, sin embargo, traemos un estudio sobre el contenido vehiculado en la tradicional media electrónica: la radio. Analisamos los spots transmitidos en la última semana de la segunda vuelta de la Campaña Presidencial de 2018, producidos y disponibilizados por los partidos en el sistema de divulgación del Tribunal Superior Electoral (TSE); estos se publicaron en la programación comercial de las emisoras de radio de todo el país. Para el análisis, categorizamos las temáticas de los spots electorales, con basis en la metodología desarrollada por Panke y Cervi (2011) y en la clasificación definida por Virginia Beaudoux y Orlando D'Adamo (2006), como puntos positivos, negativos y de contraste. En ambas campañas lo que prevaleció fue el intento de descalificación del adversario, con características predominantemente negativas.

Pallabras-clave: Comunicación Política; Spots Electorales; Campaña Electoral; Campaña Presidencial; Radio. 


\section{Introdução}

Ainda que a forma de consumo de rádio tenha mudado no decorrer das décadas, ele ainda continua sendo um dos veículos com mais audiência no país. Inicialmente, o rádio era elitizado, com a presença de poucos aparelhos. Depois, com sua "era de ouro", dominou o entretenimento e passou a ditar, inclusive, formas de consumo e configurações publicitárias. Com o advento da TV, perdeu audiência, mas seguiu como "companhia" na realização das atividades diárias. Ainda que atualmente o consumo de Internet seja ascendente e alcance, segundo o IBGE$^{1}$, quase $65 \%$ da população, o rádio segue com uma proporção ainda maior: 89\%, conforme Ibope Media² e 91\% ${ }^{3}$ de acordo com o levantamento Kantar Ibope Media, feito este ano.

É fundamental termos em mente a dimensão do país e as diferenças socioeconômicas entre suas regiões. Nem "todo mundo" está na Internet e nem todos os locais têm acesso à rede. Por sua vez, o alcance radiofônico é mais amplo, tornando-se companhia - tanto nas regiões rurais como nas urbanas - durante o deslocamento, por exemplo. A maioria dos ouvintes no país acompanha a programação via aparelhos comuns, somando 65\%. Já a audiência nos carros é de $24 \%$ e de $16 \%$ em telefones com recepção FM, conforme o estudo do Target Group Index ${ }^{4}$.

\section{Linguagem Radiofônica e Persuasão}

Ainda que estejamos inseridos em uma sociedade imagética, a comunicação sonora jornalística possui agilidade e imediatismo; no entretenimento (tanto musical quanto nos programas humorísticos), estimula a imaginação e interfere diretamente em

\footnotetext{
1 Disponível em https://g1.globo.com/economia/tecnologia/noticia/brasil-tem-116-milhoes-de-pessoas-conectadasa-internet-diz-ibge.ghtml Acesso em 13/06/19

2 Mais informações em http://www.acaert.com.br/ibope-media-divulga-infografico-que-detalha-o-consumo-de-radiono-brasil\#.XQJTxohKiyl Acesso em 13/06/19

3 Mais informações em http://www.set.org.br/set-news/levantamento-do-kantar-ibope-aponta-que-91-dosbrasileiros-ouvem-radio/ Acesso em 13/06/19

4 Dados em http://www.acaert.com.br/ibope-media-divulga-infografico-que-detalha-o-consumo-de-radio-nobrasil\#.XQJbQIhKiyK Acesso em 13/06/19
} 
estados de ânimo. 0 som estimula sensações e altera humores por se compor de quatro formas principais de linguagem e seus subtipos, conforme Panke (2019):

\begin{abstract}
A comunicação sonora é composta pela linguagem linguística (idioma, tom, voz, plasticidade); linguagem de ruídos (sonoplastia, sons do cotidiano, efeitos, simulacros do real); linguagem do silêncio (propicia a pausa necessária para assimilação de determinadas mensagens, gera o efeito de suspense, destaca informações) e linguagem musical (trilha, jingle). (PANKE, 2019, p. 25)
\end{abstract}

Portanto, a comunicação no rádio é rica em elementos sonoros que visam levar o ouvinte a construir uma imagem, relacionada à mensagem que se pretende passar. Segundo Miguel Ángel Ortiz e Jesús Marchamalo (2006) este processo se dá a partir do momento em que o som é decodificado e ganha algum significado, transformando-se em linguagem sonora. Para os autores, a linguagem sonora é capaz de transmitir conceitos, sensações e representações (2006, p.64).

Ortiz e Marchamalo (2006) coadunam com Panke (2019) ao observar que na construção da mensagem radiofônica é possível utilizar quatro elementos básicos: a música, efeitos sonoros, a palavra e o silêncio. Neste sentido, Eduardo Meditsch (2001), afirma que o texto de rádio deve ser elaborado pensando na voz do locutor ao lê-lo, uma vez que, por conter apenas elementos sonoros, algumas palavras ou termos devem ser pensados como locução e as informações devem ser precisas, para que o ouvinte possa compreendê-las. "A mensagem do rádio sofre a competição da visão (e dos demais sentidos), que está captando simultaneamente informações diferentes, passíveis de interesse e, com isso, de distrair a atenção do ouvinte" (2001, p. 183).

Robert Mcleish (2001), entretanto, afirma o poder criativo do rádio sobre os ouvintes: "Diferentemente da televisão, (...) as paisagens e sons do rádio são criados dentro de nós, podendo ter impacto e envolvimento maiores" (2001, p.16).

Trata-se de um meio cego, mas que pode estimular a imaginação, de modo que logo ao ouvir a voz do locutor o ouvinte tente visualizar o que ouve, criando na mente a figura do dono da voz. (MCLEISH, 2001, p. 15)

Desta forma, a publicidade e a propaganda utilizam estes recursos sonoros para persuadir e influenciar a opinião do receptor, utilizando apelos emocionais e afetivos, para mudar valores, crenças e hábitos. Na comunicação sonora estes apelos se 
convertem em tom de voz, trilha sonora, silêncios estratégicos, por exemplo. Neste contexto, a comunicação política também busca influenciar os cidadãos, na construção de valores e representações que levem o eleitor a escolher um determinado candidato.

Com o poder de penetração do rádio em todas as camadas sociais, ele sempre esteve presente nos planos de mídia das campanhas eleitorais no Brasil, primeiro pela instituição do Horário Gratuito de Propaganda Eleitoral (HGPE) e depois, nos anos 90, com a inserção dos spots publicitários, que são o foco deste estudo.

\section{Spots Eleitorais}

Os spots eleitorais foram usados pela primeira vez no Brasil nas eleições municipais de 1996, instituídos pela Lei 9.100, de 29 de setembro de 1995, passando a compor a série de recursos persuasivos/informativos das campanhas políticas. A utilização deste formato trouxe uma nova gramática à campanha eleitoral no Brasil, já que, ao contrário do que ocorre com o HGPE, não há a 'quebra' da programação normal do rádio e da TV, ou seja, a propaganda eleitoral é inserida na programação comercial das emissoras, junto com outras inserções comerciais, o que exige que as mensagens sejam mais breves e diretas do que no HGPE, adaptando-se aos tempos padronizados das emissoras.

Beaudoux e D’Adamo (2006) destacam que os spots eleitorais são instrumentos muito importantes dentro da campanha eleitoral na sociedade atual, uma vez que o conteúdo é totalmente produzido e controlado pelo partido político e pelo candidato, sem a mediação de jornalistas ou possibilidade de embate entre os candidatos, como ocorre em debates, por exemplo. Assim, é um importante canal de comunicação com o eleitor, principalmente nos meios eletrônicos como o rádio e a TV.

La prensa escrita provee un registro que la gente puede consumir según sus propias necesidades y tiempos, permitiendo la reexposición al mensaje cuantas veces la persona le juzgue necesario. La radio y la televisión alcanzan a públicos más amplios y diversos, llegando de 
manera más directa a los receptores. ${ }^{5}$ (BEAUDOUX e D'ADAMO, 2006, p.83)

Os autores ainda apontam que os spots se destacam 'por sua brevidade, efetividade e possibilidade total de controle da mensagem pelo emissor' (BEAUDOUX e D'ADAMO, 2006, p. 88). Além disso, têm três funções principais, segundo os autores: a) ressaltar as credenciais de um candidato, mostrando que pode ser um bom administrador público; b) atacar o adversário, mostrando o oponente como um administrador indesejável; c) responder aos ataques.

Deste modo, os pesquisadores classificam os tipos de spots eleitorais em três categorias: spot positivo, de contraste e negativo, conforme detalhado a seguir:

a) Spots positivos: servem para posicionar ideologicamente o candidato e trazem informações sobre a sua vida pública, sua biografia, as suas credenciais para ser um bom gestor;

b) Spots de contraste: servem para posicionar o candidato em relação ao outro, de forma comparativa. Pode ser uma comparação direta ou indireta, neste caso, deixando a mensagem subentendida, para que o eleitor possa fazer a relação entre os dois oponentes;

c) Spots negativos: são utilizados para descontruir a imagem do adversário, com mensagens de ataque direto.

Uma campanha eleitoral utiliza recursos emocionais para atacar os adversários e, ao mesmo tempo, promover o seu candidato. Para Weber (2004), este movimento dialético parte da constituição da imagem pública, que para a autora é "um processo de construções e desconstruções de verdades, realidades e legitimidade" (WEBER, 2004, p. 260).

Assim, Coe (2015) ressalta que em uma campanha eleitoral, a retórica política tenta mostrar aos eleitores por quê determinado candidato merece o seu voto. 0 autor destaca a teoria funcional do discurso de campanha política, desenvolvida por William

\footnotetext{
5 "A imprensa escrita fornece um registro que as pessoas podem consumir de acordo com suas próprias necessidades e tempos, permitindo a re-exposição à mensagem quantas vezes a pessoa julgar necessário. A rádio e a televisão alcançam públicos mais amplos e diversificados, alcançando os receptores mais diretamente ". (BEADOUX e D'ADAMO, 2006, p.83).
} 
Benoit, que aponta que em uma campanha política 'as mensagens fazem isso através de uma aclamação, um ataque ou uma defesa' (COE, 2015, p. 03).

Neste contexto, os spots veiculados na última semana do segundo turno das eleições presidenciais de 2018 demonstram a intenção dos dois candidatos de se posicionarem de forma distinta na mente do eleitor. Ao falar sobre posicionamento dos candidatos, Galicia (2010) afirma que o processo começa com a construção de uma imagem pública, a qual se dá a partir de dois planos que ajudam a formar a imagem do candidato na mente do eleitor. 0 primeiro diz respeito às necessidades concretas, como emprego, educação, saúde. O segundo está relacionado ao plano simbólico e utiliza questões psicológicas para a formação da imagem, tais como a paz, a confiança, a solidariedade.

\begin{abstract}
La imagen del candidato se construye en la mente del elector a través de lo que percibe de su entorno. Lo que el elector percibe es su realidad. Sin embargo, no siempre esta realidad es tangible. Existen valores que percibe, pero físicamente no los puede tocar. Cree en ellos y los reconoce socialmente. ${ }^{6}$ (GALICIA, 2010, p. 155)
\end{abstract}

São essas imagens, construídas na mente do eleitor, que são levadas em conta no momento da formulação da imagem e do discurso político. Patrick Charaudeau (2008) destaca que a construção do discurso político é uma combinação entre a razão e a emoção.

\begin{abstract}
A encenação do discurso político oscila entre a ordem da razão e a da paixão, misturando logos, ethos e pathos para tentar responder à questão que supostamente se coloca o cidadão: ' 0 que me leva a aderir a este ou àquele valor?'. Para o político, é uma questão da estratégia a ser adotada na construção de sua imagem (ethos) para fins de credibilidade e de sedução, da dramatização do ato de tomar a palavra (pathos) para fins de persuasão, da escolha e da apresentação dos valores para fins de fundamento do projeto político. (CHARAUDEAU, 2008, p. 84)
\end{abstract}

$\mathrm{Na}$ busca de um posicionamento na percepção do eleitorado, os candidatos buscam se diferenciar de seus opositores. Assim, Fara (2013) define uma campanha eleitoral como uma 'batalha comunicacional', na qual é preciso traçar estratégias que

\footnotetext{
6 "A imagem do candidato é construída na mente do eleitor através do que ele percebe do seu entorno. 0 que o eleitor percebe é a sua realidade. No entanto, essa realidade nem sempre é tangível. Existem valores que você percebe, mas fisicamente você não pode tocá-los. Acredita neles e os reconhece socialmente ". (tradução nossa; GALICIA, 2010, p.155).
} 
levem em consideração a opinião pública e o contexto social, econômico e político. Para o autor, os eleitores não votam em promessas explícitas e sim em imagens implícitas.

\section{Contexto 2018}

A campanha eleitoral para o segundo turno das eleições presidenciais de 2018 teve início em rádio e TV em 12 de outubro e terminou no dia 26 do mesmo mês, dois dias antes do segundo turno, realizado em 28 de outubro. Concorreram à presidência da república os candidatos Jair Bolsonaro, do Partido Social Liberal (PSL), pela coligação "Brasil Acima de Tudo, Deus Acima de Todos", e Fernando Haddad, do Partido dos Trabalhadores (PT), pela coligação "O Povo Feliz de Novo".

Para este artigo, analisamos os spots disponibilizados pelos partidos ao Tribunal Superior Eleitoral (TSE), os quais constam no Mapa de Mídias das emissoras de rádio, veiculados na última semana da campanha eleitoral. O Mapa de Mídias traz informações sobre o título dos spots e as datas em que devem ser veiculados; alguns materiais são transmitidos em mais de um dia, conforme definição da coordenação de campanha de cada coligação. Os spots analisados têm duração de 30 e 60 segundos e foram veiculados durante a programação comercial das emissoras de rádio de todo o Brasil, conforme determinação da justiça eleitoral.

0 Partido dos Trabalhadores (PT) disponibilizou 22 spots de rádio para a campanha de segundo turno das eleições de 2018, entre 12 e 26 de outubro. 0 Partido Social Liberal (PSL) produziu, neste mesmo período, 29 spots de rádio. 0 corpus desta pesquisa é composto pelos spots que foram veiculados pelos dois grupos na última semana da campanha eleitoral, entre 21 e 26 de outubro. São, no total, 36 spots de 30 e 60 segundos, sendo 19 do candidato Fernando Haddad e 17 do candidato Jair Bolsonaro.

Na pesquisa qualitativa, os áudios foram transcritos levando em consideração aspectos relacionados à plástica (trilha, efeito, vinheta, narração) e ao conteúdo. Após esta etapa, realizamos a classificação do material, com base na metodologia desenvolvida por Panke e Cervi (2011), na qual o conteúdo é categorizado em onze temáticas distintas: educação, saúde, segurança, infraestrutura, candidato, economia, 
Brasil, temas político-sociais, meio-ambiente, desqualificação e relações internacionais. O estudo também classificou os spots como positivos, negativos e de contraste, de acordo com nomenclatura definida por Beaudoux e D'Adamo (2006). Com a decupagem, elencamos os tipos de spots e as temáticas abordadas na reta final da campanha presidencial de 2018, pelas duas legendas.

\section{Análise de spots da campanha presidencial 2018}

A comunicação política se vale de recursos emocionais para persuadir o eleitor a escolher determinado candidato na disputa eleitoral. Desta forma, as mensagens veiculadas na campanha 2018 estavam carregadas de elementos emocionais, tais como temores, preocupações e mitos que são construídos na mente do eleitor. Isto está diretamente relacionado com os assuntos abordados. Observamos que as temáticas se vincularam a sentimentos de otimismo ou pessimismo, de acordo com a retórica adotada.

No caso dos spots analisados, quatro temas foram encontrados, entre os quais a desqualificação predominou nas peças de campanha, conforme o gráfico abaixo. Os outros assuntos foram: candidato, economia e Brasil.

FIGURA 1 - GRÁFICO TEMAS SPOTS ELEITORAIS (SEGUNDO PANKE E CERVI)

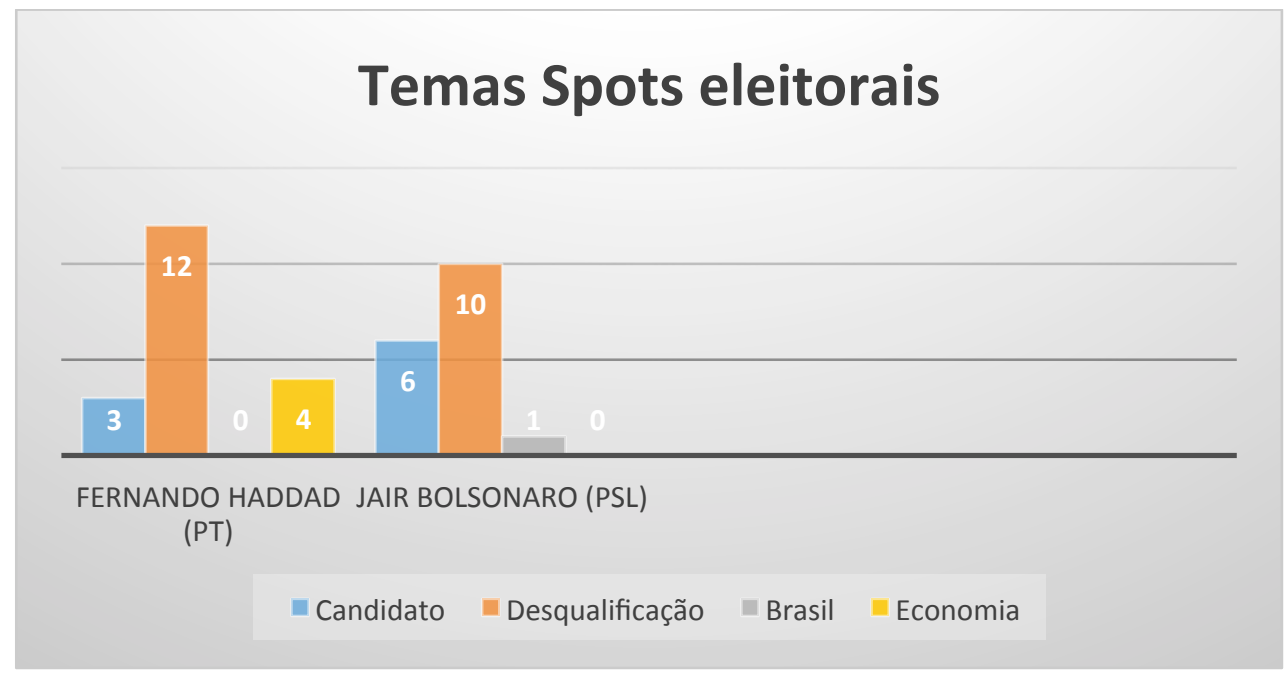

Fonte: As Autoras (2019) 
A pesquisa empírica realizada neste trabalho comprova a utilização destes recursos na construção de narrativas que levam o eleitor a preferir um candidato em detrimento de outro, baseando a decisão do voto no medo ou na repulsa. Esses sentimentos estão normalmente relacionados à temática "desqualificação", prevista na metodologia e a mais utilizada nos áudios em 2018. No trecho abaixo, por exemplo, é possível perceber o uso de tais recursos. A transcrição é do spot "Inserção 13 A", do candidato Jair Bolsonaro:

Trilha suspense - entra BG / Narrador: é, o Brasil é um país à beira do caos. Os responsáveis? Todo mundo conhece. 0 mecanismo corrupto que comanda o país há 30 anos nunca esteve tão perto de ser derrubado. $E$ quanto mais perto chegamos, mais eles ficam desesperados. Porque é aquilo né, começa com as coligações estranhas, caixa 2, dinheiro público jorrando nas campanhas milionárias, manipulação de informações. Depois vem a conta. Cargos e ministérios entregues sem critério técnico, troca de favores, toma lá dá cá, mentiras e corrupção. E aí o dinheiro volta para os partidos, abastece as campanhas e mantém os de sempre no poder. 0 resultado dessa baderna: milhões de desempregados, a maior crise econômica da história e recorde de assassinatos. É, a gente está perto de dar um fim nisso. Basta! A hora é agora! Agora é honestidade, fé e amor ao Brasil. / Abre áudio povo ovacionando o candidato / Vinheta encerramento com informações da coligação. (Grifos das autoras).

Os grifos que realizamos no texto buscam destacar os recursos sonoros (trilha e sonoplastia) utilizados para gerar tensão, primeiramente, e alívio, no final, com o fundo sonoro de pessoas ovacionando o candidato. Em relação à linguagem, vimos logo no início do spot o candidato do PSL se faz valer da estratégia de desqualificação "é, o Brasil é um país à beira do caos. Os responsáveis? Todo mundo conhece". Podemos classificar o ataque na categoria "desqualificação do grupo", pois ainda que não cite diretamente nomes, atribui a culpa de problemas nacionais aos seus potenciais adversários. No trecho em que o narrador cita, em tom sóbrio, que 'o resultado dessa baderna: milhões de desempregados, a maior crise econômica da história e recorde de assassinatos', fica evidente a tentativa de criar um medo em relação ao futuro, caso o candidato não seja eleito, uma vez que ele se coloca como a única opção para mudar a realidade do país.

Por sua vez, a campanha de Fernando Haddad buscou a bandeira da defesa da democracia para tentar desqualificar o opositor, utilizando os recursos da emoção e do 
medo da volta da Ditadura Militar, visto que Bolsonaro tinha o apoio de grande parte das Forças Armadas, conforme o texto abaixo, do spot intitulado "H8":

Trilha acelerada com sirenes de polícia, pessoas gritando por ajuda ao fundo, tiros, pessoas desesperadas, entra BG. / Narrador: Avalie se vale a pena votar no Bolsonaro só por ódio do PT. Muita gente não lembra, ou querem esquecer, que o Brasil teve uma ditadura e que matou e torturou milhares e milhares de brasileiros. Muitos tinham uma única culpa - não gostar do regime. Tortura não tem lei, pode ser em qualquer um: choque, estupro, porrada na frente dos filhos. Bolsonaro apoia a tortura. / Abre áudio Bolsonaro em entrevista a uma emissora da TV: eu sou favorável à tortura, você sabe disso. / Repete áudio / Narrador: e se você não gostar do governo dele? Bolsonaro, quem conhece a verdade não vota nele. / Vinheta encerramento com informações da coligação. (Grifos das autoras).

Já no início do spot, a trilha acelerada com sonoplastia de sirene, gritos e tiros proporciona uma atmosfera tensa que integra a retórica sonora de criar alarme e medo aos indecisos ou potenciais eleitores de Bolsonaro. Ao se referir a "ódio do PT" no texto, a campanha explicita o pensamento popular e busca minimizar seu efeito, alertando sobre as consequências que aquele sentimento poderia gerar ao eleger um candidato violento. 0 recurso da repetição da fala do candidato do PSL quando admite apoiar a tortura é uma das maneiras que o áudio possui de buscar a fixação da mensagem.

Conforme observado, ambos os áudios se valem da mesma emoção para desqualificar o adversário, despertando a insegurança e o medo no eleitorado. Entretanto, ainda que haja semelhança nos recursos emocionais com o uso da desqualificação do Outro e da qualificação de si próprio, as campanhas diferiram na escolha dos outros assuntos. É preciso destacar que alguns temas surgiram em apenas uma campanha, como por exemplo o tema economia (que foi defendido somente por Fernando Haddad) e o tema Brasil (que só foi abordado por Jair Bolsonaro).

Jair Bolsonaro falou sobre o tema Brasil em apenas um dos 17 spots analisados aquele intitulado "Inserção 17" -, sendo que esse spot se refere a questões de gênero e fala sobre a violência contra a mulher, conforme descrito no trecho abaixo:

Trilha ao fundo / Narração Bolsonaro: Minha saudação a todas as mulheres do Brasil. O PT diz que defende vocês, mas em seu governo nunca a violência contra as mulheres cresceu tanto. Nós queremos endurecer a legislação, de modo que todo aquele que cometa crime contra a mulher pague de forma integral. Juntos, vamos construir uma história de verdade, para o bem-estar de todos, em especial das nossas 
mulheres que tanto necessitam. / Vinheta encerramento com informações da coligação. (Grifos das autoras).

A rejeição ao candidato do PSL sempre foi maior no público feminino, tanto no período eleitoral como atualmente. No começo da campanha, por exemplo, ele estava com $43 \%$ de rejeição entre as mulheres 7 . 0 movimento \#EleNão, criado por mulheres em redes sociais, repercutiu nas ruas e em outros meios de comunicação, taxando Bolsonaro como o candidato "machista, racista e homofóbico". Deste modo, um dos desafios da campanha era convencer esse público que esses rótulos seriam apenas estratégias do adversário petista para desqualificá-lo. Outro trecho que destacamos neste spot foi a expressão "juntos vamos construir uma história de verdade", o que nos sugere duas leituras: primeiro, ele busca se afirmar como democrático e não autoritário; segundo, insinua que não há história prévia em prol dos direitos da mulher.

Fernando Haddad trouxe a temática da economia para quatro dos 19 spots analisados. Abaixo, a transcrição do spot intitulado "H 11":

\begin{abstract}
Música alegre entra BG / Mulher falando: Haddad, o salário não dura nem quinze dias. 0 que você vai fazer pelo povo? / Narração Haddad: tomarei três medidas imediatas no dia $1^{\circ}$ de janeiro. Vou aumentar o salário mínimo acima da inflação, inclusive para os aposentados. 0 bolsa família terá reajuste de $20 \%$ e o gás de cozinha vai custar apenas 49 reais em todo o país. Eu já fiz as contas e a decisão está tomada, agora é com você, vote 13, vamos todos pelo Brasil. / Vinheta encerramento com informações da coligação. (Grifos das autoras).
\end{abstract}

O tom de alegria da trilha sonora deste spot amplifica a mensagem linguística ao destacar as conquistas da população quando o Brasil era governado pelo grupo político de Haddad. Além disso, o candidato focou em números concretos que afetam a rotina dos brasileiros. Destacamos também a afirmação de Haddad de que "a decisão está tomada", visando afirmar postura de líder, possivelmente tentando se desvincular da pecha de manipulado pelo ex-presidente Lula, a quem estava sendo associado.

A campanha de Fernando Haddad também tentou associar a sua candidatura à manutenção do regime democrático no Brasil, buscando se aproximar dos eleitores indecisos. No spot intitulado "H19", o candidato fala que a eleição de Bolsonaro é um 'tiro no escuro' e reconhece que o PT teve erros e acertos em sua gestão.

\footnotetext{
7 Dados em <https://www1.folha.uol.com.br/poder/2018/08/cresce-a-rejeicao-das-mulheres-a-jair-bolsonaroaponta-pesquisa-datafolha.shtml $>$ Acesso em 13/06/19
} 
Ao analisar o conteúdo dos spots eleitorais utilizados pelos dois candidatos, é possível perceber que ambas as campanhas foram negativas, se dedicando mais a desconstruir a imagem do adversário do que, de fato, apresentar seus candidatos e trazer propostas mais concretas para governar o país, conforme descrito no gráfico abaixo.

FIGURA 2 - GRÁFICO CLASSIFICAÇÃO SPOTS ELEITORAIS (SEGUNDO BEAUDOUX E D’ADAMO)

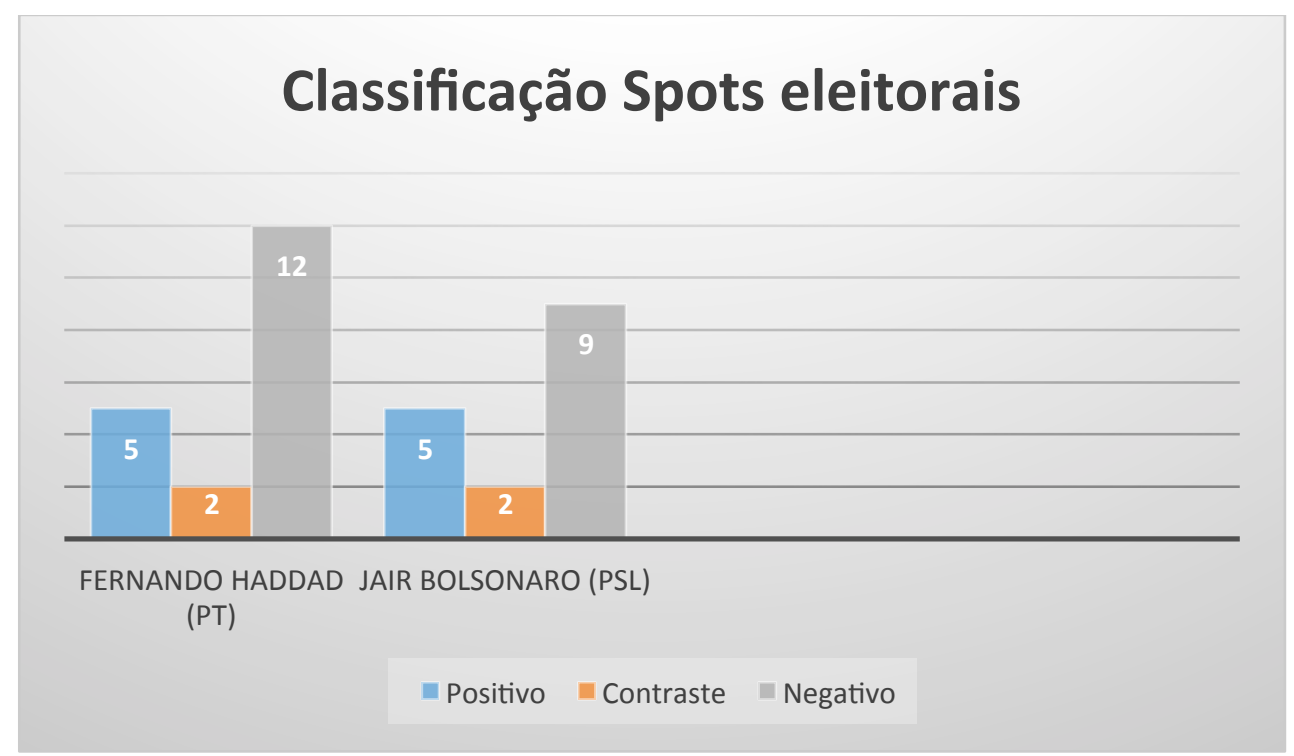

Fonte: As Autoras (2019)

É perceptível pela análise dos spots a tensão vivenciada pelo eleitorado durante o pleito de 2018. A polarização na política brasileira se evidenciou com a extrema direita seguindo para o segundo turno e elegendo como foco retórico o Partido dos Trabalhadores como sinônimo de corrupção e "inimigo único", conforme as regras de Domenach (2001). Isso fica evidente em trechos retirados das duas campanhas, principalmente nos spots veiculados em 26 de outubro, último dia da propaganda em rádio e TV. No spot de Jair Bolsonaro, intitulado "Inserção 27", o candidato fala "Eu sou o contrário do que eles são. Eu sou uma ameaça aos corruptos". O mesmo recurso foi utilizado na campanha do PT: no spot intitulado "H 19", Fernando Haddad cita: "Neste domingo, você vai escolher entre dois caminhos para o futuro. 0 mundo já reconhece que Bolsonaro representa violência. É um risco para a democracia, um salto no escuro". 
Além disso, o pleito de 2018 foi marcado como a eleição das fake news e do uso de aplicativos de mensagens como grande instrumento de manipulação. Os resultados do gráfico acima refletem esta tensão, com mais que o dobro de spots negativos em relação aos positivos e apenas dois de contraste. Nos positivos estão elencados os que traziam uma defesa do caráter e das qualidades de cada candidato.

\section{Considerações Finais}

No período analisado, foram disponibilizados pelos partidos políticos às emissoras de rádio de todo o país 19 spots eleitorais distintos de Fernando Haddad, da Coligação "O Povo Feliz de Novo", e 17 spots de Jair Bolsonaro, da coligação "Brasil Acima de Tudo, Deus Acima de Todos". Importante ressaltar que alguns spots foram veiculados mais de uma vez, em dias distintos, e que a quantidade de inserções é definida pela justiça eleitoral. A campanha de Haddad utilizou apenas spots de 30 segundos, e a de Bolsonaro veiculou peças de 30 e de 60 segundos.

Em ambas as campanhas, o tema que mais se verificou nos spots veiculados em rádio entre os dias 21 e 26 de outubro foi o de desqualificação, seguido do tema candidato, em que o presidenciável se apresenta à população e fala de suas realizações na vida pública. 0 resultado reflete o clima final de campanha, quando os ânimos tendem a estar mais acirrados.

Nas eleições mais polarizadas da história do Brasil, portanto, é possível perceber a tentativa de desconstrução da imagem dos dois candidatos, seja pela possibilidade de limitar as instituições democráticas (no caso dos ataques a Jair Bolsonaro), seja pela relação do candidato com pessoas e partidos investigados por corrupção (no caso dos ataques a Fernando Haddad). Somente o candidato do Partido dos Trabalhadores (PT) abordou o tema economia em sua campanha, enquanto o candidato do PSL, tentou se aproximar de nordestinos e mulheres, além de destacar a valorização da pátria em um dos spots analisados.

Percebemos a tentativa dos candidatos de se aproximar dos eleitores indecisos e reforçar a campanha em regiões onde estavam perdendo votos, segundo as pesquisas 
eleitorais. No caso do candidato do PSL Jair Bolsonaro, essa intenção aparece em três dos spots analisados. No primeiro, ele se dirige diretamente às mulheres, em uma clara tentativa de aproximação com o público feminino, após várias manifestações populares nas ruas e nas redes sociais contra sua candidatura, dentro do movimento \#EleNão. Em outros dois spots, o candidato busca fortalecer a sua campanha no nordeste do país, como fica claro no spot intitulado "Inserção 18", em que o narrador, com sotaque nordestino, fala: "Nordestino tem palavra e eu sei que o senhor também tem, capitão. É no seu olho que eu tô olhando. Até a glória, se Deus quiser meu novo presidente”, em uma referência direta ao candidato.

Por sua vez, Haddad tenta se reafirmar como um líder democrático com formação intelectual, visando se desvincular da imagem de "fantoche" do ex-presidente Lula. Na reta final da campanha, constatamos que o rádio foi utilizado para reforçar suas qualidades, mas, principalmente, para alertar os indecisos. Tanto nas trilhas sonoras quanto nos discursos orais, sua fala reforçou a desqualificação e o medo da eleição de Bolsonaro com a possível perda de conquistas.

Tendo em vista a possibilidade de novos estudos relacionados à comunicação eleitoral no meio radiofônico, o presente artigo pode servir de subsídio para pesquisadores da área da comunicação política, especialmente os dedicados a observarem as produções sonoras. Aqui o enfoque foi a veiculação dos spots eleitorais; a mesma metodologia, entretanto, pode ser empregada na investigação dos programas de rádio do Horário Gratuito de Propaganda Eleitoral (HGPE).

\section{Referências bibliográficas}

BEAUDOUX, Virginia; Orlando, D’Adamo. Comunicación política y campañas electorales. Análisis de una herramienta comunicacional: el spot televisivo. México, 2006.

CHARAUDEAU, Patrick. Discurso Político. São Paulo: Editora Contexto, 2008.

COE, Kevin. Rethorical Political. In MAZZOLENI, Gianpietro; BARNHURST, Kevin; IKEDA, Ken'ichi; MAIA, Rousiley; WESSLER, Hartmut. (Org.). The International Encyclopedia of Political Communication. 1ed.London: Wiley-Blackwell, 2015. 
DOMENACH, Jean Marie. A propaganda política. 2001. Disponível em: http://cultvox.locaweb.com.br/livros_gratis/apropagandapolitica.pdf. Acesso em: 30 de março de 2001.

FARA, Carlos. Estrategias de campaña. In Acciones para una buena comunicación en campañas electorales. Buenos Aires, 2013.

GALICIA, Javier. Posicionamiento. In Treinta claves para entender el poder. México, Piso 15:

2010.

MCLEISH, Robert. Produção de rádio - um guia abrangente de produção radiofônica. Volume 62. São Paulo: Editora Summus, 2001.

MEDITSCH, Eduardo. O Rádio na Era da Informação: Teoria e Técnica do Novo Radiojornalismo. Florianópolis: Editora UFSC, 2001.

ORTIZ, Miguel Ángel; MARCHAMALO, Jesús. Técnicas de Comunicação pelo Rádio - a prática radiofônica. São Paulo: Edições Loyola, 2006.

PANKE, L.; CERVI, E. Análise da Comunicação Eleitoral: uma proposta metodológica para os estudos de HGPE. Revista Contemporânea, Salvador, v. 9, n. 3, p. 390-403, 2011. http://www.comunicacaoeleitoral.ufpr.br/publicacoes/686873-558.pdf

PANKE, L. Criação publicitária em rádio. Curitiba, Intersaberes, 2019.

WEBER, Maria Helena. Imagem Pública. In RUBIM, Antônio. Comunicação e Política, conceitos e abordagens. Salvador: Editora UFBA, 2004. 